\title{
Different flight behaviour of the endangered scarce large blue butterfly Phengaris teleius (Lepidoptera: Lycaenidae) within and outside its habitat patches
}

\author{
Piotr Skórka • Piotr Nowicki • Magdalena Lenda • \\ Magdalena Witek • Ewa B. Śliwińska • \\ Josef Settele $\cdot$ Michal Woyciechowski
}

Received: 26 April 2012/ Accepted: 28 January 2013/Published online: 7 February 2013

(C) The Author(s) 2013. This article is published with open access at Springerlink.com

\begin{abstract}
Understanding individual movements in heterogeneous environments is central to predicting how landscape changes affect animal populations. An important but poorly understood phenomenon is behavioural response to habitat boundaries and the way animals cross inhospitable matrix surrounding habitat patches. Here, we analyze movement decisions, flight behaviour, and activity of the endangered scarce large blue Phengaris (Maculinea) teleius, focusing on the differences among the patterns observed in patch interior, at patch boundaries and within matrix. The probability of crossing an external patch boundary, regardless of the land use in the adjacent area, was considerably lower than crossing a 'control line' within patch interior. Movement distances, flight durations and net squared displacement were largest in matrix, while
\end{abstract}

Electronic supplementary material The online version of this article (doi:10.1007/s10980-013-9855-3) contains supplementary material, which is available to authorized users.

P. Skórka $(\bowtie) \cdot$ E. B. Śliwińska

Institute of Zoology, Poznan University of Life Sciences,

Wojska Polskiego 71 C, 60-625 Poznan, Poland

e-mail: skorasp@poczta.onet.pl

P. Nowicki · M. Woyciechowski

Institute of Environmental Sciences, Jagiellonian

University, Gronostajowa 7, 30-387 Kraków, Poland

M. Lenda

Institute of Nature Conservation, Polish Academy of

Sciences, Mickiewicza 33, 31-120 Kraków, Poland similarly smaller at patch boundaries and in patch interior. The distribution of angles between successive movements was clearly clustered around $0^{\circ}$ (indicating flight in a straight line) in matrix and at patch boundaries, but not in patch interior. There were no differences in time spent on foraging, resting and ovipositing between patch interior and boundaries, but the first two activities rarely, and oviposition never, happened in matrix. Our results suggest that although $P$. teleius adults do not avoid using the resources located in the boundaries of habitat patches, they often return to the interior of the patches when crossing their boundaries. However, having entered the matrix the butterflies perform relatively long and straight flights. The estimated probability of emigration and net squared distance implies that the dispersal between local populations is common in this species in the studied area.

Keywords Dispersal - Fragmentation - Maculinea . Metapopulation · Movement $\cdot$ Patch boundary

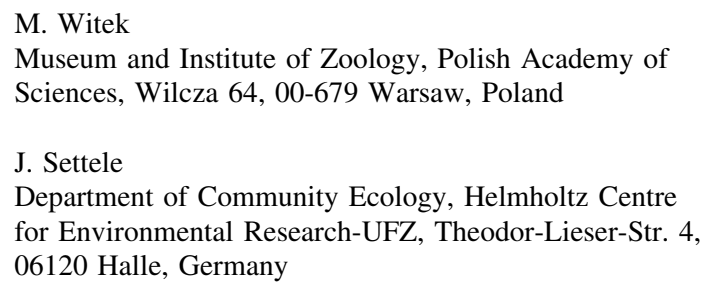




\section{Introduction}

In landscapes altered by human activity many species are forced to live in habitat patches that are spatially isolated from each other (Hanski 1999; Debinski and Holt 2000; Bergman and Landin 2001; Fahrig 2003; Trakhtenbrot et al. 2005). Consequently, dispersal is a key process making it possible for the local populations to be functionally connected into a metapopulation system despite spatial isolation of their habitat patches (Levins 1970; Hanski 1999; Fleishman et al. 2002; Bowne and Bowers 2004).

Many authors studying animal dispersal in metapopulations have focused on the effects of local patch area and isolation (Hanski 1994; Matter 1997; Moilanen and Nieminen 2002). However, such a traditional approach tends to overlook other potentially important factors (Tischendorf and Fahrig 2000; Crone et al. 2001; Schultz and Crone 2001). Among such factors, of particular importance are individual behaviours at patch boundaries (Ovaskainen 2004; Tischendorf et al. 2005) and movement strategy in inhospitable environment separating patches termed matrix (Ricketts 2001; Ross et al. 2005; Kuefler et al. 2010).

Since crossing patch boundary is the first step in emigration, propensity to do so strongly affects the proportion of emigrants (Stamps et al. 1987; Schtickzelle and Baguette 2003). However, boundary crossing may depend on boundary type (Eycott et al. 2012; Schultz et al. 2012). It may be expected that dispersing individuals should easily cross boundaries of low habitat contrast (e.g. those between meadows with and without the foodplant of a focal species), but not hard boundaries between contrasting habitats (e.g. between meadow and forest) (Ries and Debinski 2001; Ross et al. 2005; Haynes and Cronin 2006; Kuefler et al. 2010; Eycott et al. 2012). In turn, movement patterns in matrix determine emigrant chances of reaching other habitat patches (Crone and Schultz 2008; Eycott et al. 2012). For example, these chances are strongly reduced if animals entering matrix move only short distances or tend to return to their natal patch (Conradt et al. 2000; Ries and Debinski 2001; Ross et al. 2005). Conversely, long distances and straight paths of animals moving in matrix may lead to a greater displacement (Kuefler et al. 2010; Schultz et al. 2012) and higher probability of reaching a suitable habitat patch (Schtickzelle and Baguette 2003).
Dispersal may be sex-biased as predicted by several theoretical models (Perrin and Mazalov 2000; Gros et al. 2008) and often confirmed empirically (Bergman and Landin 2002; Nowicki and Vrabec 2011; Schultz et al. 2012). If females are more mobile their dispersal allows the effective colonisation of empty patches (Bergman and Landin 2002) while dispersal restricted to males does not. Male dispersal, although often ignored, may also crucially contribute to gene flow among local populations (Piaggio et al. 2009; Solmsen et al. 2011). However, sex-specific behaviour may change depending on whether the individuals are in the habitat patch interior, at the patch boundaries or in matrix (Schultz et al. 2012). For example, males may be more willing to cross habitat patch boundaries than females but once in matrix, they may move lower distances than female. This has important consequences for predicting levels of functional connectivity across the landscape and, hence, the persistence of metapopulations, but empirical data are still scarce (Ovaskainen 2004; Schultz et al. 2012). In this paper we describe how movements and other activities (foraging, resting and ovipositing) of the endangered scarce large blue butterfly Phengaris (Maculinea) teleius (Lycaenidae) differ between habitat patch interior, patch boundary and matrix. We tested the following predictions:

(1) The probabilities of crossing the patch boundary and emigration depend on boundary type, being higher for low-contrast boundaries than for highcontrast ones.

(2) If there are inter-sexual differences in dispersal, the more mobile sex should be characterised by higher probability of crossing habitat patch boundaries as well as longer and more linear movements.

(3) One should expect longer movement distances, longer time spent flying and larger net displacement at patch boundaries and in matrix as compared to patch interior. Independently from the above, angles between successive movements in matrix and at boundaries may be more clustered around $0^{\circ}$ (indicating continuous flight in a straight line sensu Turchin 1998) than in patch interior (implying zig-zag flights) (Crist et al. 1992; Kindvall 1999; Roslin 2000; Doncaster et al. 2001). 


\section{Methods}

Study species and area

The scarce large blue P. teleius is one of the most endangered butterflies in Europe (Thomas 1995; Wynhoff 1998; Settele et al. 2005). It has a highly specialized life-style, depending on two crucial resources. Females lay their eggs into the flowerheads of the Great Burnet Sanguisorba officinalis foodplants, where the larvae feed for their first weeks (Thomas 1995). The same plant is also the predominant nectar source for adult butterflies. Having reached their fourth instar, the larvae drop to the ground and are taken by the workers of Myrmica ants to their nest, where they lead a parasitic life, feeding on ant brood (Thomas et al. 1998). The host ants of P. teleius are several species of Myrmica: mostly M. scabrinodis, M. rubra and M. rugulosa (Thomas et al. 1989; Wynhoff et al. 2008; Witek et al. 2010, 2011).

The study was carried out in the vast complex of wet meadows located in the Vistula River, west of the Kraków city centre (southern Poland; Fig. 1). The meadows represent various types, however the dominant one is the Molinietalia association with the following typical plant species: Molinia caerulea, Deschampsia caespitosa, Achillea ptarmica, Angelica sylvestris, Carex hartmannii, Cirsium palustre, Galium uliginosum, Lychnis flos-cuculi, Trollius europaeus, S. officinalis. In recent decades a large part of the meadows have been abandoned and an invasion of shrubs, alien goldenrods, reeds and trees has followed (Skórka et al. 2007). Over 60 patches of S. officinalis were present in these meadows (Nowicki et al. 2007) (Fig. 1). The mean patch size was $2.9 \pm 0.7$ ha (range: $0.005-33 \mathrm{ha}$ ) and the distances between neighbouring patches were usually within the range of 100-300 m (Nowicki et al. 2007). These foodplant patches constitute habitat patches of $P$. teleius, since the aforementioned host ant species are widespread and abundant in all meadow types in our study area (Witek et al. 2008, 2010).

\section{Study design}

In order to assess the effect of various habitat boundaries on the probability of $P$. teleius emigration from the patch, six types of patch boundaries of different contrast were defined. The boundary types, listed in the order of decreasing contrast, included boundaries: (1) between a foodplant patch and a forest (difference in vegetation height $|d|=1,500 \mathrm{~cm}$; the percentage share of this boundary type in the total length of all patch boundaries in our study system $p s=18 \%$ ), (2) between a foodplant patch and a road $(|d|=130 \mathrm{~cm} ; p s=19 \%)$, (3) between a foodplant patch and an arable field $(|d|=100 \mathrm{~cm}$; $p s=5 \%$ ), (4) between a foodplant patch and a mown meadow $(|d|=90 \mathrm{~cm} ; p s=6 \%)$, (5) between a foodplant patch and reeds $(|d|=30 \mathrm{~cm}$; $p s=19 \%$ ), (6) between a foodplant patch and a meadow without this plant $(|d|=10 \mathrm{~cm} ; p s=29 \%)$. All boundaries but one were resource boundaries sensu Schultz et al. (2012). The boundary between a patch with foodplant and mown meadow could be regarded as a structural boundary (Schultz et al. 2012), because habitats on both sides of the boundary line differed only in height of vegetation (due to intensive mowing two times

per year) and both contained the foodplant. All the investigated boundaries were sharp, there was no "ecotone" (transition zone) between the butterfly habitats and the matrix and thus it was straightforward to delineate boundary line (the foodplants grew in high densities within patches, but they were not present in the adjacent areas). In each case we selected at least $80 \mathrm{~m}$ long straight line section of a boundary.

In each of the boundary types one point, located in the middle of the $80 \mathrm{~m}$ section, was selected, where butterflies were released and their behaviour was observed. Butterflies were captured at the patch and marked individually with a number on their right underwing. They were then put into small paper bags and were placed in a cooler box (at $10{ }^{\circ} \mathrm{C}$ temperature) for $10 \mathrm{~min}$ to calm down (for the rationale see Schultz 1998). Subsequently the butterfly was taken out, gently placed on a foodplant, and observed. Butterflies were always released by placing them on a host plant located inside the patch within $1 \mathrm{~m}$ from the boundary line.

Because capturing butterflies and keeping them in paper bags could influence their behaviour, we compared the behaviour in a sample of 27 (15 females and 12 males) individuals randomly encountered in the patch interior with a similar number of butterflies captured, kept in a cooler, and released. Because the recorded parameters (i.e. movement distances, turning angles and flight activity; see below) did not differ 


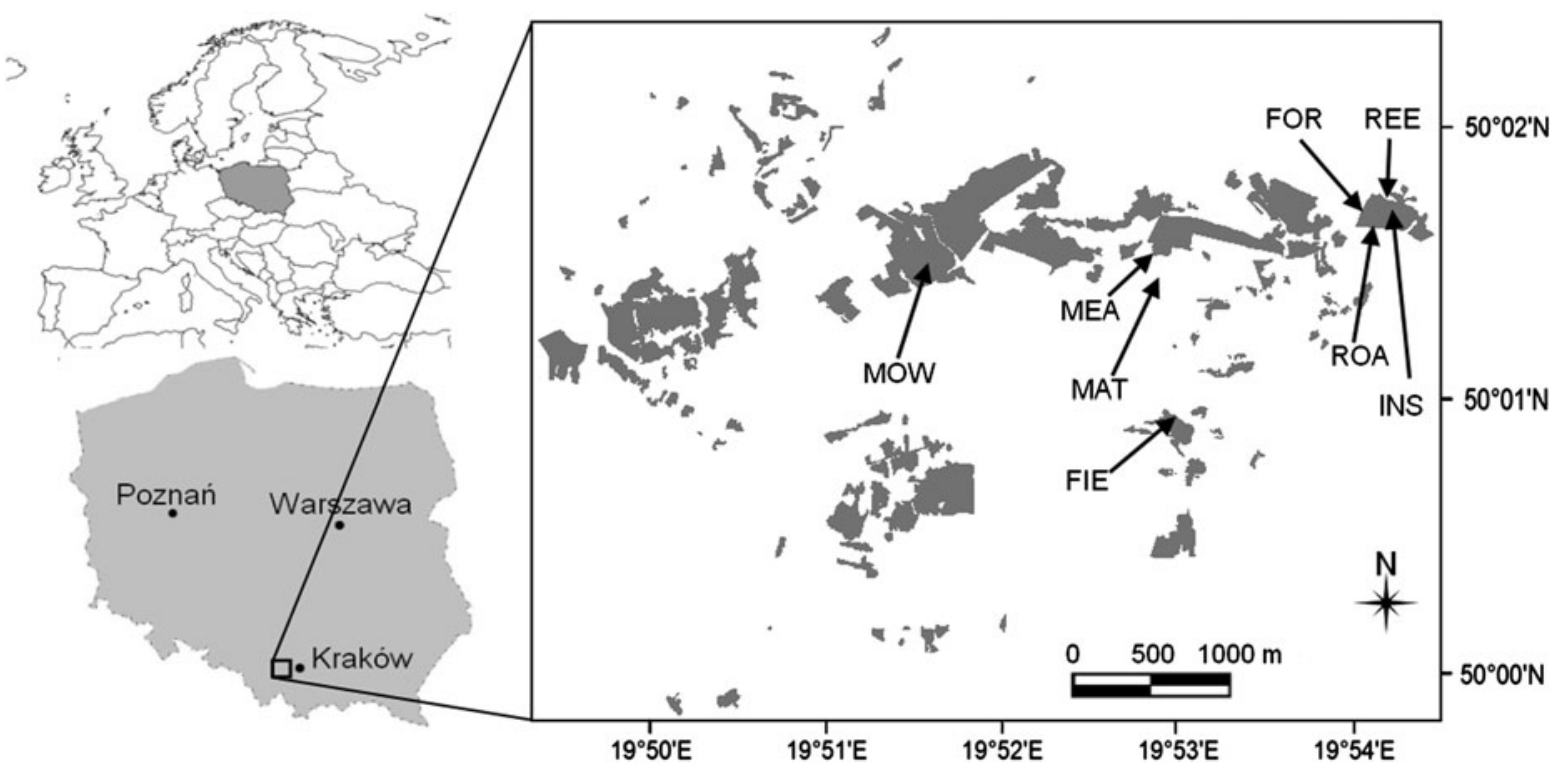

Fig. 1 Map of foodplant patches of Phengaris teleius in the Kraków region, southern Poland. Arrows indicate locations of the different boundary types where butterflies were released. Acronym explanations: FOR boundary with forest, ROA

significantly between the two groups we assumed that the effect of the experimental manipulation was neglectable.

We also released butterflies in the centre of the habitat patch and they constituted a control group for the butterflies released at the boundaries as well as in the matrix (see below). In the centre of the habitat patches we established a 'control line' (imaginary boundary) at the mid point of which butterflies were released. Finally, to assess $P$. teleius behaviour in the matrix we released butterflies outside the habitat patch. The matrix selected was a meadow with flowering plants and with a high density of Myrmica nests but without $S$. officinalis, which is the most common matrix type in our study area. The release point was located $75 \mathrm{~m}$ from the habitat patch boundary. The procedure of behavioural observations in patch interior as well as in matrix was identical as for the butterflies released at habitat patch boundaries.

The observers followed the butterflies, keeping at the distance of about $5 \mathrm{~m}$ so as not to disturb butterfly behaviour. Wooden sticks with numbered flags were placed wherever the butterfly stopped. Subsequently, for each butterfly we measured the distances between stopping points as well as the angles between successive movements. We measured up to ten distances per boundary with road, FIE boundary with arable field, MOW boundary with mown meadow, REE boundary with meadow invaded by reed, $M E A$ boundary with meadow without foodplant, INS habitat patch interior, MAT matrix

individual to prevent the inclusion of flights that were certainly within-patch movements. We also recorded the time the butterfly spent flying, foraging, resting and ovipositing (in females). In addition, we recorded if a butterfly (1) crossed the boundary and (2) emigrated from the patch. Crossing was recorded whenever the butterfly crossed the boundary line. Emigration was recorded when the butterfly once crossed the boundary line and flew at least $20 \mathrm{~m}$ from the boundary or reached another habitat patch.

We conducted detailed behavioural observations for at least 30 individuals ( 15 females and 15 males) for each habitat patch boundary type, patch interior and matrix. Additionally, to obtain more accurate estimates of the probability of crossing habitat patch boundaries we released ca. 20 more butterflies at each boundary type. The only measurement taken for these additional butterflies was a record of whether the butterfly crossed the boundary, emigrated from the natal patch or returned to it. We never used the same individual butterfly twice during the observations.

It is important to note that each boundary type, patch interior and matrix were selected to be similar in respect to the density of Myrmica ants (overall mean $\pm \mathrm{SE}=3.5 \pm 0.3$ nest per $40 \mathrm{~m}^{2}$ as assessed at three $20 \times 2 \mathrm{~m}$ transects for each release point; 
one-way ANOVA $\left.F_{7,16}=0.307, P=0.940\right)$ and the density of $S$. officinalis flowerheads (overall mean \pm $\mathrm{SE}=69.4 \pm 4.2$ as assessed at ten $1 \mathrm{~m}$ circular plots for each release point except for the matrix, one-way ANOVA $\left.\mathrm{F}_{6,63}=1.891, P=0.096\right)$.
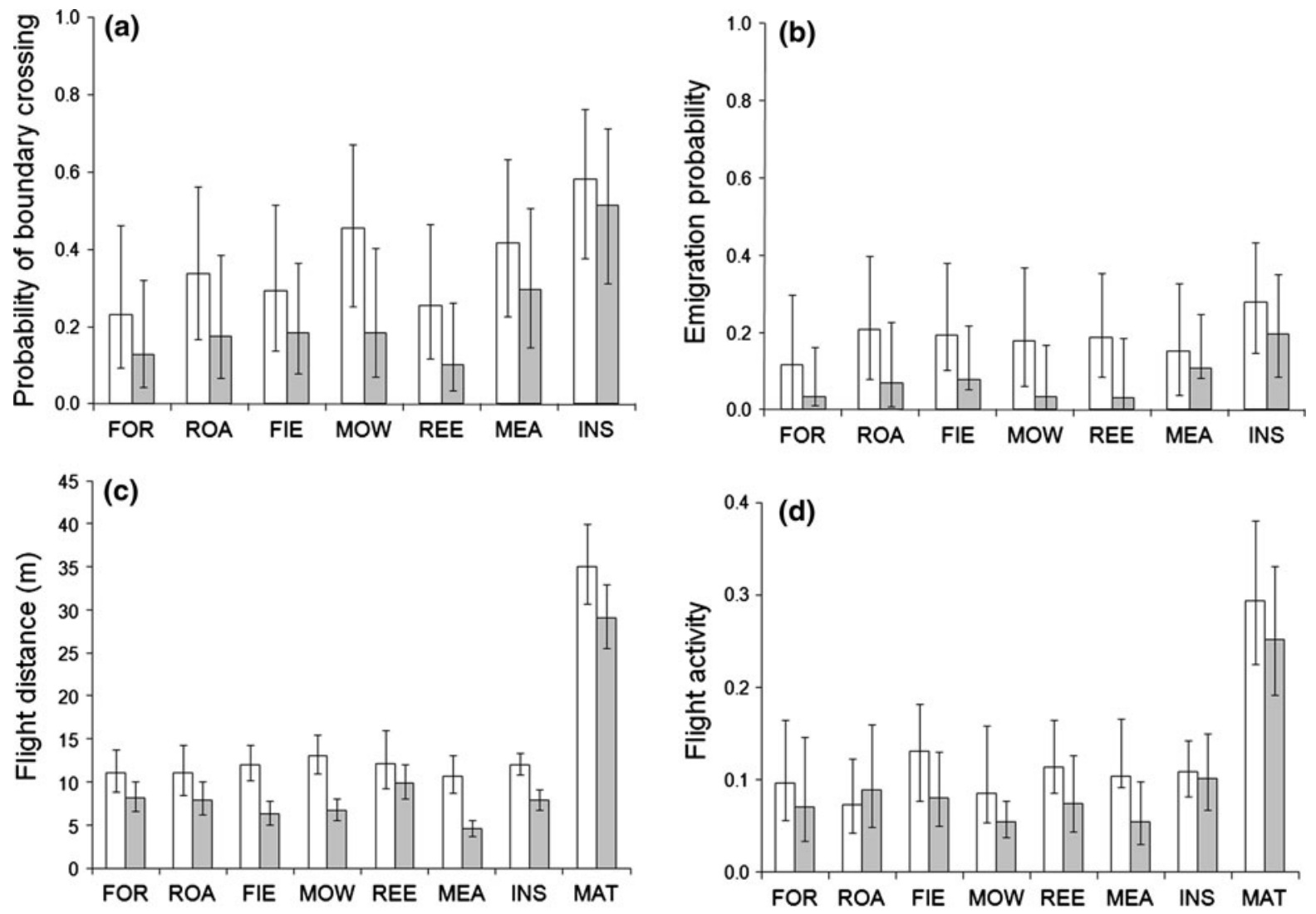

The study was carried out between 10th July and 10th August in 2005 and 2006. Observations were conducted between 10 a.m. and 4 p.m. in favourable weather conditions (minimum temperature of $20{ }^{\circ} \mathrm{C}$, maximum wind of 3 on the Beaufort Scale, maximum

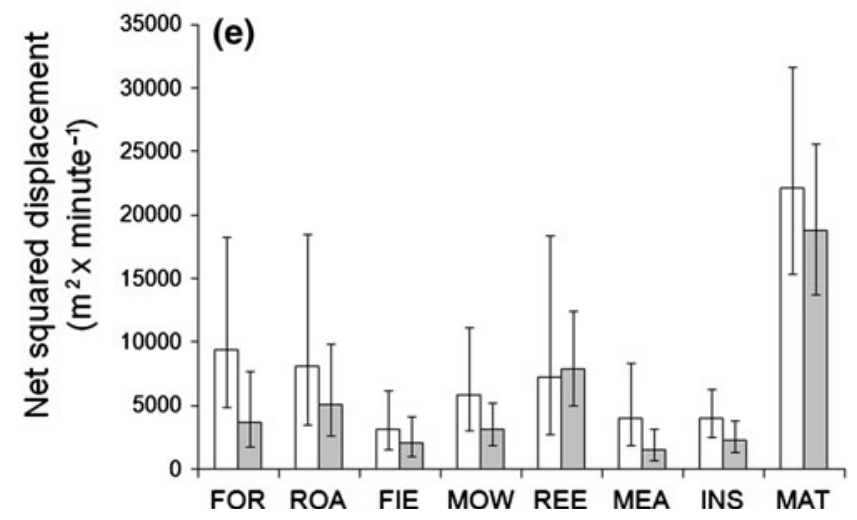

Fig. 2 Comparison of a probabilities of boundary crossing, b probabilities of emigration, c movement distances, $\mathbf{d}$ flight activity (i.e. proportion of time spent flying), and e net squared displacement in females (white bars) and males (grey bars) of 
cloud cover of $50 \%$ ). In total 313 individuals were examined and 1,533 distances were measured, with additional 218 individuals used to estimate the probabilities of crossing habitat patch boundaries and emigration.

\section{Statistical analysis}

A generalized linear mixed model (GLMM) with logit-link function and binomial error variance was applied to test for the differences in the probability of crossing the habitat patch boundary as well as of emigration (non-returns were treated as emigration). Explanatory factors in the model were patch boundary type including the control line (imaginary boundary) in patch interior, sex, and their interaction. Temperature was used as a covariate, whereas the year of the study was treated as a random factor. Non-parametric Spearman correlation coefficient was calculated to test if the rate of boundary crossing and probability of emigration were correlated with the contrast of the boundaries (including the imaginary boundary inside the habitat patch).

To compare distances covered by butterflies at various boundary types, in patch interior and in matrix we used a GLMM with identity link function. Explanatory factors were release site (all boundary types, patch interior and matrix), sex and their interaction. Temperature was again included as a covariate, while butterfly ID and year of the study constituted random factors. The same GLMM structure was applied to compare flight activity, defined as the proportion of time spent flying, as well as the duration of foraging, resting and egg laying at various release sites. Flight activity was calculated as the time spent by the individual in flight divided by the total time of its observation. The GLMM was also used to test effects of boundary type, matrix and patch interior and sex on the net squared displacement (NSD) per time unit of individual butterflies. NSD is a squared Euclidean distance from the start to position after $n$ moves of the animal movement trajectory (Turchin 1998).

We used Watson $U^{2}$ test and Williams-Fischer test (Fisher 1993) to compare respectively the means of turning angles and their distributions among various boundary types, patch interior, and matrix. The turning angle distributions were symmetrical in all the cases and they were expressed in $30^{\circ}$ intervals. For instance the turning angle of $15^{\circ}$ is equivalent to the angle of $-15^{\circ}$ or $345^{\circ}$ in terms of the circular statistic.

The GLMMs were calculated in SAS 9.1, while the turning angle analysis was done in the Oriana 2.0 software.

\section{Results}

Probability of boundary crossing and probability of emigration

The probability of crossing the control line within patch interior was significantly higher than in the case of any type of real patch boundary $\left(\mathrm{GLMM} \mathrm{F} \mathrm{F}_{6,374.3}=4.321\right.$, $P<0.001, n=462$ butterflies; Fig. 2a). On the other hand, we did not find significant differences in the probabilities of crossing for different types of real boundaries $\quad\left(\mathrm{GLMM} \quad \mathrm{F}_{5,320.6}=1.621, \quad P=0.154\right.$; Fig. 2a, control line inside habitat patch excluded, $n=375)$. Altogether $94(25 \%)$ of 375 investigated butterflies crossed the habitat patch boundary, but 53 $(56 \%)$ of them later returned to the natal patch. The analysis restricted to the remaining fraction of 41 $(11 \%)$ individuals regarded as emigrants, also revealed no significant effect of boundary type (GLMM $F_{5,322.1}$ $=1.634, P=0.151$; control line inside habitat patch excluded, Fig. $2 \mathrm{~b}, n=375$ butterflies).

Females crossed the external habitat patch boundaries twice as often as males (79 females (35\%) versus 47 males $(20 \%)$; GLMM $F_{1,323.5}=10.452$, $P=0.001$; Fig. 2a, $n=375$ butterflies) and the probability of emigration (non-return) among individual crossing the boundary was also twice higher in females than in males (33 females $(9 \%$ ) vs 16 males (4 \%); GLMM $\mathrm{F}_{1,325.8}=5.815, P=0.016$; Fig. $2 \mathrm{~b}$, $n=375$ butterflies). The interaction between boundary type and sex as well as the effects of temperature and year proved to be nonsignificant in all the cases.

There was no statistically significant correlation between the probability of boundary crossing and the boundary contrast, both for females $\left(r_{\mathrm{s}}=-0.678\right.$, $P=0.094, n=7$ boundary types, including imaginary one in the interior of the habitat patch) and males $\left(r_{\mathrm{s}}=-0.643, P=0.119, n=7\right)$. We also did not find any statistically significant correlation between the probability of emigration and the boundary contrast both for females $\left(r_{\mathrm{s}}=-0.321, P=0.482\right.$, $n=7)$ and males $\left(r_{\mathrm{s}}=-0.486, P=0.268, n=7\right)$. 
Movement distances and flight activity at patch boundaries, in patch interior, and in matrix

Distances covered by butterflies did not differ among boundary types or between the boundaries and patch interior, but they were over three times shorter than movement distances in the matrix $\left(\right.$ GLMM $\mathrm{F}_{7,1218}=$ 37.158, $P<0.001, n=313$ butterflies; Fig. 2c). Similarly, the proportion of time spent flying was higher in the matrix, and lower in other locations $\left(\right.$ GLMM F $_{7,287}=3.444, P<0.001, n=313$ butterflies; Fig. 2d), with no particular differences between patch interior and boundaries or among boundary types (Tukey post hoc tests: $P>0.05$ in each case).

Females typically flew longer distances than males $\left(\right.$ GLMM F $_{1,1218}=26.191, P<0.001$, Fig. $\left.2 \mathrm{c}\right)$, but on the other hand the proportion of time spent flying was similar in both sexes (GLMM $F_{1,287}=1.723, P=$ 0.201, Fig. 2d). Among all other effects tested in the models, only butterfly ID significantly influenced movement distance (estimate \pm SE: $0.10 \pm 0.02$, $\mathrm{Z}=4.15, P<0.001$ ), which implies strong heterogeneity in mobility among individuals.

Turning angles at patch boundaries, in patch interior, and in matrix

The mean turning angle between successive movements did not differ among all the investigated locations (Watson-Williams $F$ test, $\mathrm{F}_{7,1358}=1.046, P=0.397$ ). However, the analysis of the angle distributions showed that they were strongly clustered around $0^{\circ}$ in butterflies released at patch boundaries (concentration coefficient $=1.845$; mean angle $\pm \mathrm{SE}=4.8^{\circ} \pm 5.5^{\circ}$ ) and
Fig. 3 Female and male distributions of the turning angles in $P$. teleius movements in patch interior $(\mathbf{a}, \mathbf{b})$, at patch boundaries $(\mathbf{c}, \mathbf{d})$ and in matrix $(\mathbf{e}, \mathbf{f})$
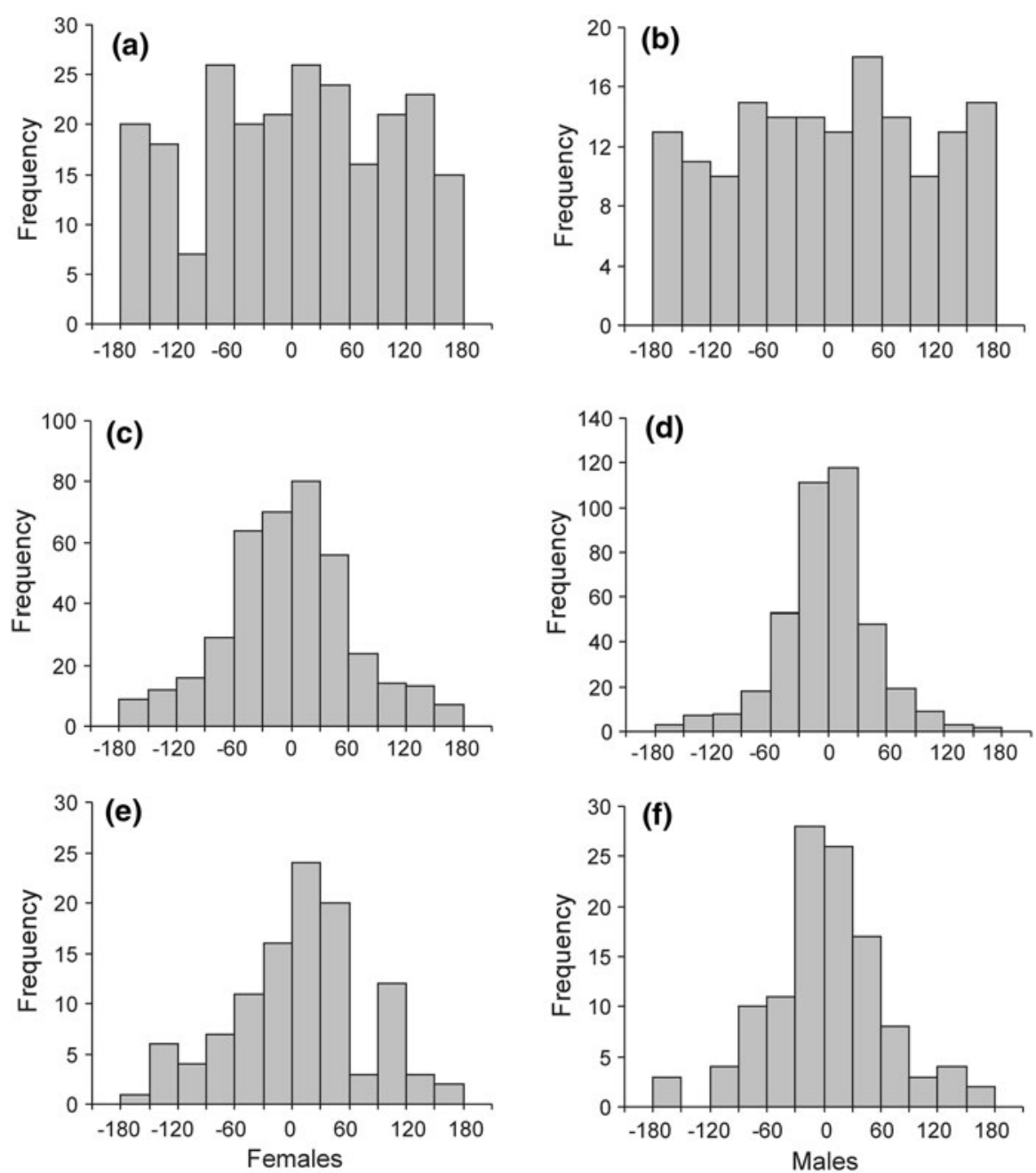
in matrix (concentration coefficient $=1.223$; mean angle $\pm \mathrm{SE}=0.7^{\circ} \pm 5.5^{\circ}$ ), but not in those released in patch interior, for which the distribution was fairly uniform (concentration coefficient $=0.294$; mean angle $\pm \mathrm{SE}=2.2^{\circ} \pm 21.3^{\circ} ;$ Fig. 3). In addition, female turning angles (concentration coefficient $=1.530$; mean angle $\pm \mathrm{SE}=1.3^{\circ} \pm 5.4^{\circ}$ ) were less concentrated around $0^{\circ}$ than male one (concentration coefficient $=0.982 ;$ mean angle $\pm \mathrm{SE}=2.0^{\circ} \pm 2.4$; $U$ Watson test, $U^{2}=0.782, \mathrm{df}_{1}=602, \mathrm{df}_{2}=681$, $P<0.001$; Fig. 3), implying that zig-zag movements were performed more frequently by the former sex.

The outcome of the $U^{2}$ Watson tests applied for comparisons of the turning angle distributions between the investigated locations are given in Table S1 in the Supplementary Material. In general, the distributions of turning angles were similar for various boundary types, although we found a slightly more peaked distribution in the case of the road boundary. Nevertheless, it must be emphasised that any differences between road boundary and other boundary types in this respect became nonsignificant when Bonferroni correction for multiple testing was applied.

The rate of area exploration by butterflies at patch boundaries, in patch interior, and in matrix

The NSD of $P$. teleius individuals was statistically higher in matrix as compared with patch interior and boundaries $\left(\mathrm{GLMM} \mathrm{F}_{7,279.4}=16.193, P<0.001, n=\right.$ 313 butterflies; with Tukey post hoc test; Fig. 1e). There was no apparent influence of boundary type on the NSD when tested versus patch interior (Tukey post hoc tests: all $P>0.05$ ). However, the NSD at the reed boundary was higher than at the boundaries with field and meadow without the foodplant (Tukey post hoc test: $P<0.05)$. Overall, the NSDs of females was higher than in males (GLMM $F_{1,279.4}=10.376, P=0.001$, $n=313$; Fig. 1e) at all boundaries, in the patch interior and in the matrix (nonsignificant interaction term between sex and releasing site in GLMM $\mathrm{F}_{7,279.2}=$ 0.696, $P=0.675, n=313$; Fig. 1e). Any other factor considered in the analysis played a nonsignificant role.

Behaviour at patch boundaries, in patch interior and in matrix

Time spent on foraging and resting by $P$. teleius individuals was significantly shorter in matrix as compared with patch interior and boundaries (foraging: GLMM $\mathrm{F}_{7,301}=2.398, P=0.021, n=230$ butterflies; resting: GLMM $\mathrm{F}_{7,533}=2.602, \quad P=0.012$; $n=291$; Fig. 4). There was no apparent influence of boundary type on the duration of aforementioned activities, except for shorter duration of resting at the road boundary (Tukey post hoc test: $P<0.05$ when tested vs patch interior). Neither sex nor any other factor considered in the analysis played a significant role.
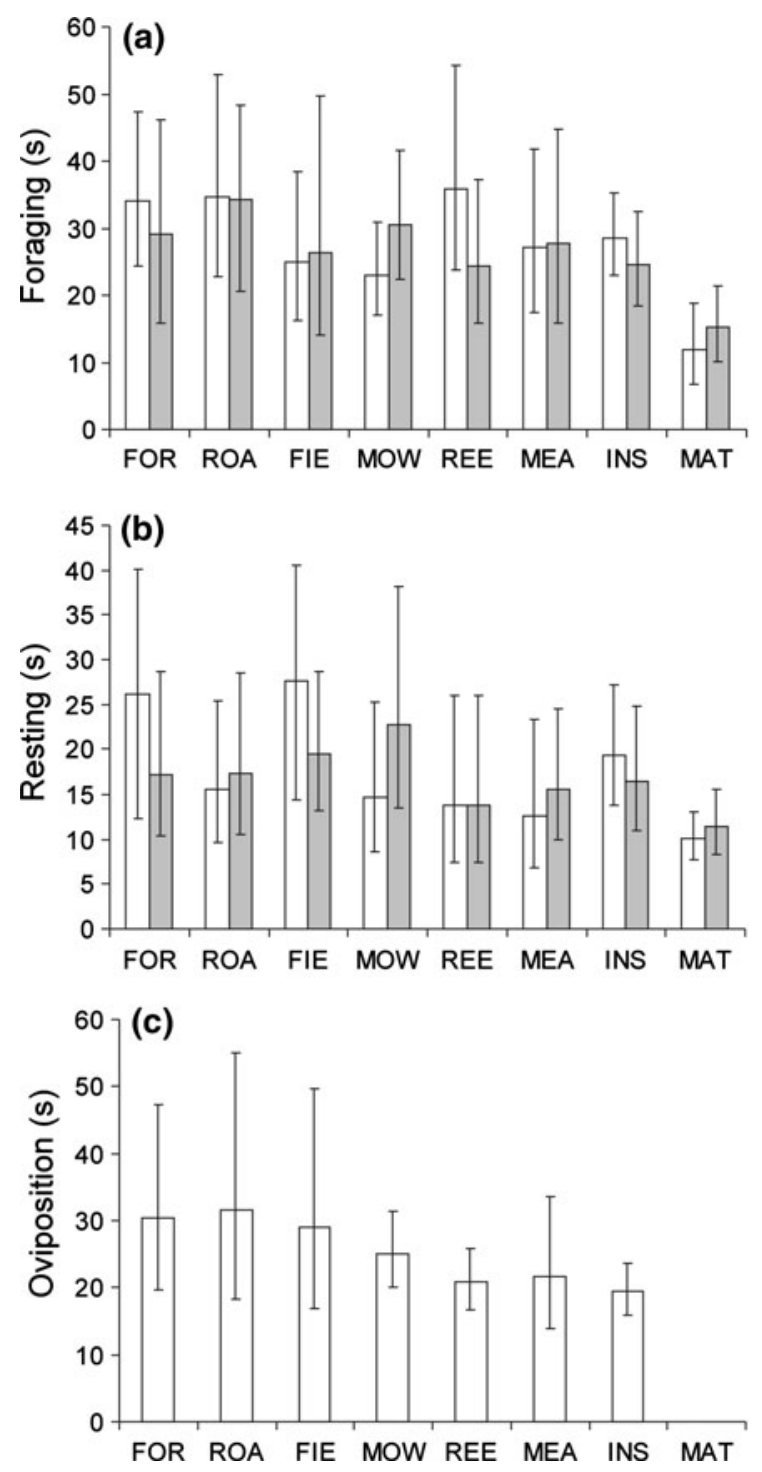

Fig. 4 Comparison of duration of a foraging, $\mathbf{b}$ resting, and c oviposition in females (white bars) and males (grey bars) of $P$. teleius at various habitat patch boundaries as well as in patch interior and in matrix. For explanations see Figs. 1 and 2 
Female oviposition time was similar between patch interior and boundaries as well as among different boundary types (GLMM $\mathrm{F}_{6,87}=0.108, P=0.996$, $n=56$ ovipositing females; Fig. 4). Matrix was excluded from the model as no cases of oviposition could be observed there, which is quite obviously due to the lack of foodplants. Interestingly, the oviposition time was positively related to temperature (estimate $\pm \mathrm{SE}: 0.321 \pm 0.157$, GLMM $\mathrm{F}_{1,87}=4.618, P=$ 0.035). Concerning random factors, it was also significantly affected by butterfly ID (estimate \pm SE: $0.13 \pm 0.06, \mathrm{Z}=2.17, P=0.015)$, but not by year.

\section{Discussion}

In the light of our results it appears P. teleius adults use the resources located both in the centre and at the edges of their habitat patches. We recorded no differences in the duration of foraging, resting and ovipositing between patch interior and patch boundaries. However, our study has demonstrated that external boundaries of habitat patches may constitute a barrier to $P$. teleius movements, since the probability of crossing such boundaries was significantly lower than in the case of a control line within patch interior. Avoidance of boundary crossing may have serious consequences for the functioning of the metapopulations. Theoretical metapopulation models assume that emigration is a stochastic process depending on the frequencies of animal encounters with their patch boundary and thus it is a function of the ratio of patch perimeter to its area (Hanski 1994; Haddad 1999; Golden and Crist 2000). Our results, as well as those of several earlier studies (Merckx et al. 2003; Schtickzelle and Baguette 2003; Conradt and Roper 2006; Kuefler et al. 2010; Schultz et al. 2012), suggest that the behaviour at patch boundaries also plays a role and consequently the probability of emigration may be lower than predicted purely on the basis of patch geometry.

The proportion of emigrants assessed in the present study at ca. $10 \%$ butterflies is in good agreement with the coarse estimates of the proportions of P. teleius individuals changing habitat patches derived for the same study area on the basis of mark-recapture studies (Nowicki et al. 2005b, 2007). However, the advantage of present analysis is that it not only documents the pattern, but also helps to understand the underlying processes, indicating that the moderate level of emigration stems from the facts that the prevailing majority of butterflies do not cross patch boundaries, and among those that do so more than half return to the natal patch. Moreover, not all emigrants become immigrants elsewhere; in other words emigration is not tantamount with successful reaching another habitat patch. Although assessing this aspect of dispersal was beyond the scope of our research, the study by Nowicki and Vrabec (2011) revealed that mortality during the dispersal was fairly low, at maximum $28 \%$ in the year when butterflies numbers peaked above carrying capacity and there was an emigration outbreak, but close to zero in 'normal' years, in a Czech region with both habitat configuration and matrix composition being very similar to those in our study area. The mortality of dispersal is highly dependent on the geometry of the landscape as well as the dispersal biology of the species but several other studies suggested that the mortality during dispersal may be low in butterfly metapopulations (Matter 2006; Rabasa et al. 2007; Fric et al. 2010; but see Wahlberg et al. 2002). Moreover, our estimates of the NSD showed that $P$. teleius may explore relatively large area in very short time when moving in the matrix. The low interpatch patch distances, which are usually between 100 and $300 \mathrm{~m}$, in the study region implies that butterflies are able to cover large area during a few minutes of movements in matrix. This is also in agreement with our earlier study (Nowicki et al. 2007) documenting a little fragmented metapopulation with very high patch occupancy (93-100\%).

Virtually all of the results concerning inter-sexual differences suggest that females are the more mobile sex. They had considerably higher probability of crossing patch boundaries, and lower probability of subsequent return to the natal patch, which is consistent with the higher female emigration rate reported for P. teleius (Nowicki and Vrabec 2011). We also found that $P$. teleius females flied significantly longer distances than males. They also explored larger area in time unit than males. These are interesting results because heavy body weight of females may negatively affect, for example, flight activity (Kingsolver and Srygley 2000). However, body weight is also often strongly correlated with speed of flight and, thus, distance covered (Dudley and Srygley 1994; Dudley 2000). Larger distances covered by females of P. teleius were reported also by Körösi et al. (2012). These 
findings are in contrast with those studies reporting higher mobility of males in butterfly populations. For example, Schultz et al. (2012) found that males were more mobile and willing to cross habitat patch boundaries than females in another lycaenid, Fender's blue (Icaricia icarioides fenderi). The discrepancy can potentially be explained by different resource requirements in these species. The $S$. officinalis foodplant is also a nectar source for P. teleius (Thomas et al. 1998), but Icaricia icarioides fenderi uses as nectar sources other plants than its lupine (Lupinus spp.) foodplants (Schultz and Crone 2001). Consequently, while females of Icaricia icarioides fenderi stay close to their foodplant patches as oviposition sites, males may be attracted to leave them in search of nectar sources. In turn, our explanation for higher emigration propensity in $P$. teleius females is in agreement with the concept of the fitness benefits of distributing reproductive effort over several patches (den Boer 1968; Brown and Ehrlich 1980). All concerned, females probably have higher chances of reaching other habitat patches. Therefore gene flow among local populations of P. teleius appears more dependent on females. More importantly, since even a single female is able to successfully colonise a vacant habitat patch, femalebiased dispersal has positive consequences for colonisation rate, thus enhancing metapopulation viability.

Our study is one of the few that examined animal behaviour at various types of habitat patch boundaries (cf. Kuefler et al. 2010; Schultz et al. 2012). Interestingly, all the investigated boundary types turned out to have fairly similar permeability for P. teleius. Some earlier studies showed that crossing high-contrast boundaries, like those with forests, is avoided particularly by butterflies (Ricketts 2001; Ross et al. 2005; Eycott et al. 2012; but see Kuefler et al. 2010). In our analysis, the boundary with forest, also had the lowest permeability, but the difference in relation to other boundary types was nonsignificant and rather small. Even the boundary between foodplant patch and the meadow without the foodplant, with little structural contrast between the two habitats, acted as a barrier restricting butterfly movements. The above findings confirm the concept of Schultz et al. (2012) that butterfly movements are shaped primarily by their responses to resource distribution rather than to physical structure of habitats. Strong site-fidelity towards foodplant patches is an especially beneficial strategy in strong specialist species, such as Phengaris butterflies. In addition, home ranging behaviour is also likely to play a role. Hovestadt and Nowicki (2008), who reported it for P.teleius, suggested that keeping close to the place of eclosion is an adaptation to myrmecophily.

To our surprise, we have learned that mown fragments also restrict butterfly movements. It is generally believed that a mosaic of mown and abandoned fragments within meadows is helpful for local population persistence of grassland species (Cremene et al. 2005). This is, however, based on the implicit assumption that animals move freely between different parts of their patches. As we demonstrated, this assumption may not necessarily be valid. Even if mown fragments are relatively small in area and hence they have no effect on the overall availability of resources, they may increase functional fragmentation of local populations, possibly impeding gene flow and reducing effective population size. From the conservation point of view, it is yet another argument for mowing to be done after the flight period, in the case of $P$. teleius habitats preferably no earlier than in mid September (cf. Grill et al. 2008). Mowing should also be done before the flight period in the second week of June every 5-7 years (Wynhoff et al. 2011). Such early mowing is needed when the soil is rich in nutrient or wet (as in our study region), because it is the only way to reduce the coverage of reed and willows effectively (Wynhoff et al. 2011).

Working in a natural landscape is often disadvantageous with respect to experimental design. Our data on the behaviour of P.teleius at different boundaries, in the patch interior and in the matrix have some limitations which should be taken into account when generalizing to other areas and species. All the butterflies within a boundary treatment were released at one point. Having replicates within boundary types would be desirable. However, a sampling design of that nature was unattainable for practical reasons, since, despite extensive efforts in the field, it proved impossible to find other release points with comparable resource densities and boundary shape within our study area. The behaviour of the P. teleius, including movements, is highly dependent on two critical resources; the larval foodplant $S$. officinalis and the Myrmica host ants (Maes et al. 2004; Batáry et al. 2007, 2009; Wynhoff et al. 2008; Van Langevelde and Wynhoff 2009). To make it possible to take into account the strong effect of a resource availability 
which is highly variable, several dozen replicates per boundary type would be needed. This was not feasible owing to logistic constraints, such as, for example, the single and relatively heavy cooler box in which the butterflies were cooled before release. Therefore, instead, we decided to control for resource availability by choosing release points with the same foodplant and host ant densities, which were also average for the entire study area. We believe that such an approach made it possible to focus on the main objective of the study which was a comparison of permeability for different patch boundary types, rather than on all the factors determining flight behaviour at boundaries, which are likely to be dominated by the effects of resource densities, which have already been documented in other papers. Adding more release points to one edge line would also result in other uncontrolled effects, such as, for instance, a different boundary amount, perceptible to the butterflies, at release points near the end of the boundary line. Moreover, from another of our studies (Skórka et al. under preparation) on the dispersal behaviour of P. teleius and other lycaenid butterfly species at road verges, we have learned that road crossing by this species is mostly affected by resource density and the replicates of the boundary had no impact on the overall results.

Further conservation implications of our study concerns the ongoing debate about the applicability of corridors and stepping stones as measures facilitating animal movements (Primack 2002). Although we did not test these two approaches, the results on the behaviour of $P$. teleius inside habitat patches, at their boundaries and in matrix may provide some clues how to increase connectivity between local populations. While the effectiveness of corridors is sometimes questioned (Simberloff et al. 1992; Mann and Plummer 1995), in butterflies they have been frequently shown to enhance inter-patch movements (Dirig and Cryan 1991; Sutcliffe and Thomas 1996; Tewksbury et al. 2002). Assuming that entering a corridor does not require crossing a boundary (which is not always the case), corridors may also be expected to increase the numbers of P. teleius individuals emigrating from their natal patches. This, however, does not seem desirable in our study system. Approximately $10 \%$ emigration, which in fact appears quite typical for Phengaris butterflies and other butterflies (see review in Nowicki et al. 2005a), has been proven to be enough to ensure rapid colonisation of vacant patches within reach (Nowicki et al. 2007; Van Langevelde and Wynhoff 2009). Furthermore, it should be noted that the densities of investigated populations were at an average level in both years of the study (authors' unpublished data). Since Phengaris populations are known to experience strong fluctuations (Nowicki et al. 2009), and positive density-dependence of emigration has been reported in this genus (Nowicki and Vrabec 2011), one should expect that the proportions of individuals leaving their natal patches recorded in the present study are at least doubled in years when the population density is high.

A great majority of emigrants move between the nearest neighbouring patches, and only a few percent of them undertake genuine dispersal that makes it possible to reach distant patches (Hovestadt et al. 2011). Consequently, conservation efforts should be focused on increasing the distances covered by emigrants. As our analysis demonstrated, movements within patches, both in their interior and at boundaries, are very short and they are likely to be so within corridors composed of a similar habitat. In contrast, we found that $P$. teleius covered much longer distances in straight movements and explored larger area in matrix and spent less time there on resting, foraging or ovipositing. The findings of other authors also indicated that animals try to cross matrix relatively quickly (Miyatake et al. 1995; Schultz 1998; Conradt and Roper 2006; Schtickzelle et al. 2007; Schultz et al. 2012). However, moving through matrix may be associated with lower supply of resources, higher mortality due to predation, and low probability of finding another habitat patch (Rankin and Burchsted 1992; Zollner and Lima 1999; Schtickzelle and Baguette 2003; Stamps et al. 2005; Schtickzelle et al. 2007). Therefore, in order to facilitate movements of $P$. teleius through matrix the corridors of low quality may be a useful solution. These should be elongated landscape structures (road verges, forest edges) which can canalise dispersal of butterflies between habitat patches. P. teleius is known to utilise very small habitat fragments of a few tens of square metres (Nowicki et al. 2007) so if host-plant was present in the corridors it could actually lead to reproduction there and possibly lower dispersal. If the primary aim is to increase species mobility across a landscape the corridors should not provide enough host plants which is in line with results of the experiments published by Haddad and Tewksbury 
(2005). Nevertheless, they should contain other flowering plants so that butterflies could replenish the energy resources during dispersal.

Alternatively, stepping stones that are much smaller landscape elements that corridors may be also useful solution. In specific terms, stepping stones for P. teleius should be located 50-100 m apart, possibly with higher numbers near habitat patches so that butterflies that flew out of the patches are encouraged to continue their movements rather than to return to the patches. Stepping-stones have also an important practical advantage over corridors: they are much easier to create in agricultural landscapes, typically characterised by diverse ownership and mosaic land use. The setting a corridor (as defined above) or managing the existing one would require agreements with all the owners of the land it is going to cross, while in case of stepping stones there is some flexibility in choosing their locations, which among others gives freedom to negotiate only with the landowners that are eager to cooperate. For example in many agricultural landscapes, the stepping stones for this butterfly would be easy to create within the framework of the agroenvironmental schemes by establishing field margins. This is a clear advantage in a region with very diverse landownership like our study area.

Acknowledgments We thank two anonymous referees for helpful comments on earlier version of this manuscript. The study was funded by the European Commission within its RTD project MacMan (EVK2-CT-2001-00126) as well as by the Polish Committee of Scientific Research within its grant SPUB3024. PN has been supported by the by the Polish National Science Centre (Grant No. N304 064139).

Open Access This article is distributed under the terms of the Creative Commons Attribution License which permits any use, distribution, and reproduction in any medium, provided the original author(s) and the source are credited.

\section{References}

Batáry P, Örvössy N, Kőrösi Á, Vályi-Nagy M, Peregovits L (2007) Microhabitat preferences of Maculinea teleius (Lepidoptera: Lycaenidae) in a mosaic landscape. Eur J Entomol 104:731-736

Batáry P, Körösi Á, Örvössy N, Kövér S, Peregovits L (2009) Species-specific distribution of two sympatric Maculinea butterflies across different meadow edges. J Insect Conserv 13:223-230
Bergman K-O, Landin J (2001) Distribution of occupied and vacant sites and migration of Lopinga achine (Nymphalidae: Satyrinae) in fragmented landscape. Biol Conserv 102:183-190

Bergman K-O, Landin J (2002) Population structure and movements of a threatened butterfly (Lopinga achine) in a fragmented landscape in Sweden. Biol Conserv 108:361-369

Bowne DR, Bowers MA (2004) Interpatch movements in spatially structured populations: a literature review. Landscape Ecol 19:1-20

Brown JH, Ehrlich PR (1980) Population biology of the checkerspot butterfly Euphydryas chalcedonia. Oecologia 47:239-251

Conradt L, Roper TJ (2006) Non-random movement behavior at habitat boundaries in two butterfly species: implications for dispersal. Ecology 87:125-132

Conradt L, Bodsworth EJ, Roper TJ, Thomas CD (2000) Nonrandom dispersal in the butterfly Maniola jurtina: implications for metapopulation models. Proc Biol Sci 267: $1505-1510$

Cremene C, Groza G, Rakosy L, Schileyko AA, Baur A, Erhardt A (2005) Alterations of steppe-like grasslands in Eastern Europe: a threat to regional biodiversity hotspots. Conserv Biol 19:1606-1618

Crist TO, Guertin DS, Wiens JA, Milne BT (1992) Animal movement in heterogenous landscapes: an experiment with Eleodes beetles in shortgrass prairie. Funct Ecol 6:536-544

Crone EE, Schultz CB (2008) Old models explain new observations of butterfly movement at patch edges. Ecology 89:2061-2067

Crone EE, Doak D, Pokki J (2001) Ecological influences on the dynamics of a field vole metapopulation. Ecology 82:831-834

Debinski DM, Holt RD (2000) A survey and overview of habitat fragmentation experiments. Conserv Biol 14:342-355

den Boer PJ (1968) Spreading of risk and stabilization of animal numbers. Acta Biotheor 18:165-194

Dirig R, Cryan JF (1991) The status of silvery blue subspecies (Glaucopsyche lygdamus lygdamus and G. l. couperi: Lycaenidae) in New York. J Lepidopt Soc 45:272-290

Doncaster CP, Rondinini C, Johnson PCD (2001) Field test for environmental correlates of dispersal in hedgehogs Erinaceus europaeus. J Anim Ecol 70:33-46

Dudley R (2000) The biomechanics of insect flight: form, function, evolution. Princeton University Press, Princeton, $\mathrm{NJ}$

Dudley R, Srygley RB (1994) Flight physiology of Neotropical butterflies: allometry of airspeeds during natural free flight. J Exp Biol 191:125-139

Eycott AE, Stewart GB, Buyung-Ali LM, Bowler DE, Watts K, Pullin AS (2012) A meta-analysis on the impact of different matrix structures on species movement rates. Landscape Ecol 27:1263-1278

Fahrig L (2003) Effects of habitat fragmentation on biodiversity. Annu Rev Ecol Evol Syst 34:487-515

Fisher NI (1993) Statistical analysis of circular data. Cambridge University Press, Cambridge

Fleishman E, Ray C, Sjögren-Gulve P, Boggs CL, Murphy DD (2002) Assessing the roles of patch quality, area, and isolation in predicting metapopulation dynamics. Conserv Biol 16:706-716 
Fric Z, Hula V, Klimova M, Zimmermann K, Konvicka M (2010) Dispersal of four fritillary butterflies within identical landscape. Ecol Res 25:543-552

Golden DM, Crist TO (2000) Experimental effects of habitat fragmentation on rove beetles and ants: patch area or edge? Oikos 90:525-538

Grill A, Cleary DFR, Stettmer C, Bräu M, Settele J (2008) A mowing experiment to evaluate the influence of management on the activity of host ants of Maculinea butterflies. J Insect Conserv 12:617-627

Gros A, Hovestadt T, Poethke HJ (2008) Evolution of sex-biased dispersal: the role of sex-specific dispersal costs, demographic stochasticity, and inbreeding. Ecol Model 219: 226-233

Haddad NM (1999) Corridor and distance effects on interpatch movements: a landscape experiment with butterflies. Ecol Appl 9:612-622

Haddad NM, Tewksbury JJ (2005) Low-quality habitat corridors as movement conduits for two butterfly species. Ecol Appl 15:250-257

Hanski I (1994) A practical model of metapopulation dynamics. J Anim Ecol 63:151-162

Hanski I (1999) Metapopulation ecology. Oxford University Press, Oxford

Haynes KJ, Cronin JT (2006) Interpatch movement and edge effects: the role of behavioural responses to the landscape matrix. Oikos 113:43-54

Hovestadt T, Nowicki P (2008) Investigating movement within irregularly shaped patches: analysis of MRR data using randomisation procedures. Israel J Ecol Evol 54: $137-154$

Hovestadt T, Binzenhöfer B, Nowicki P, Settele J (2011) Do all inter-patch movements represent dispersal? A mixed kernel study of butterfly mobility in fragmented landscapes. J Anim Ecol 80:1070-1077

Kindvall O (1999) Dispersal in a metapopulation of the bush cricket Metriptera bicolour (Orthoptera: Tettigoniidae). J Anim Ecol 68:172-185

Kingsolver JG, Srygley RB (2000) Experimental analyses of body size, flight and survival in pierid butterflies. Evol Ecol Res 2:593-612

Kőrösi Á, Örvössy N, Batáry P, Harnos A, Peregovits L (2012) Different habitat selection by two sympatric Maculinea butterflies at small spatial scale. Insect Conserv Divers 5:118-126

Kuefler D, Hudgens B, Haddad NM, Morris WF, Thurgate N (2010) The conflicting role of matrix habitats as conduits and barriers for dispersal. Ecology 91:944-950

Levins R (1970) Extinction. In: Gerstenhaber M (ed) Some mathematical questions in biology. American Mathematical Society, Providence, pp 77-108

Maes D, Vanreusel W, Talloen W, Van Dyck H (2004) Functional conservation units for the endangered Alcon Blue butterfly Maculinea alcon in Belgium (Lepidoptera, Lycaenidae). Biol Conserv 120:229-241

Mann CC, Plummer ML (1995) Are wildlife corridors the right path? Science 270:1428-1430

Matter SF (1997) Population density and area: the role of within and between patch processes. Oecologia 110:533-538

Matter SF (2006) Changes in landscape structure decrease mortality during migration. Oecologia 150:8-16
Merckx T, Van Dyck H, Karlsson B, Leimar O (2003) The evolution of movements and behaviour at boundaries in different landscapes: a common arena experiment with butterflies. Proc Biol Sci 270:1815-1821

Miyatake T, Kawasaki K, Kohama T (1995) Dispersal of male sweetpotato weevils (Coleoptera: Curculionidae) in fields with or without sweet potato plants. Environ Entomol 24:1167-1174

Moilanen A, Nieminen M (2002) Simple connectivity measures in spatial ecology. Ecology 83:1131-1145

Nowicki P, Vrabec V (2011) Evidence for positive densitydependent emigration in butterfly metapopulations. Oecologia 167:657-665

Nowicki P, Settele J, Thomas JA, Woyciechowski M (2005a) A review of population structure of Maculinea butterflies. In: Settele J, Kühn E, Thomas JA (eds) Studies in the ecology and conservation of butterflies in Europe. Species ecology along a European Gradient: Maculinea butterflies as a model, vol 2. Pensoft Publishers, Sofia, Moscow, pp 144149

Nowicki P, Witek M, Skórka P, Settele J, Woyciechowski M (2005b) Population ecology of the endangered butterflies Maculinea teleius and M. nausithous and the implications for conservation. Popul Ecol 47:193-202

Nowicki P, Pepkowska A, Kudlek J, Skórka P, Witek M, Settele J, Woyciechowski M (2007) From metapopulation theory to conservation recommendations: lessons from spatial occurrence and abundance patterns of Maculinea butterflies. Biol Conserv 140:119-129

Nowicki P, Bonelli S, Barbero F, Balletto E (2009) Relative importance of density-dependent regulation and environmental stochasticity for butterfly population dynamics. Oecologia 161:227-239

Ovaskainen O (2004) Habitat-specific movement parameters estimated using mark-recapture data and a diffusion model. Ecology 85:242-257

Perrin N, Mazalov M (2000) Local competition, inbreeding, and the evolution of sex-biased dispersal. Am Nat 155:116-127

Piaggio AJ, Navo KW, Stihler CW (2009) Intraspecific comparison of population structure, genetic diversity, and dispersal among three subspecies of Townsend's big-eared bats, Corynorhinus townsendii townsendii, C.t.pallescens, and the endangered C. t. virginianus. Conserv Genet 10: 143-159

Primack RB (2002) Essentials of conservation biology, 3rd edn. Sinauer Associates, Sunderland, MA

Rabasa SG, Gutierrez D, Escudero A (2007) Metapopulation structure and habitat quality in modelling dispersal in the butterfly Iolana iolas. Oikos 116:793-806

Rankin MA, Burchsted JCA (1992) The cost of migration in insects. Annu Rev Entomol 37:533-559

Ricketts TH (2001) The matrix matters: effective isolation in fragmented landscape. Am Nat 158:87-99

Ries L, Debinski DM (2001) Butterflies responses to habitat edges in the highly fragmented prairies of Central Iowa. J Anim Ecol 70:840-852

Roslin T (2000) Dung beetle movement at two spatial scales. Oikos 91:323-335

Ross JA, Matter SF, Roland J (2005) Edge avoidance and movement of the butterfly Parnassius smintheus in matrix and non-matrix habitat. Landscape Ecol 20:127-135 
Schtickzelle N, Baguette M (2003) Behavioural responses to habitat patch boundaries restrict dispersal and generate emigration-patch area relationships in fragmented landscapes. J Anim Ecol 72:533-545

Schtickzelle N, Joiris A, Van Dyck H, Baguette M (2007) Quantitative analysis of changes in movement behaviour within and outside habitat in specialist butterfly. BMC Evol Biol 7:4. http://www.biomedcentral.com/1471-2148/7/4

Schultz CB (1998) Dispersal behavior and its implications for reserve design for a rare Oregon butterfly. Conserv Biol 12: 284-292

Schultz CB, Crone EE (2001) Edge-mediated dispersal behaviour in a prairie butterfly. Ecology 82:1879-1892

Schultz CB, Franco AMA, Crone EE (2012) Response of butterflies to structural and resource boundaries. J Anim Ecol 81:724-734

Settele J, Kühn E, Thomas JA (2005) Studies in the ecology and conservation of butterflies in Europe. Species ecology along a European gradient: Maculinea butterflies as a model, vol 2. Pensoft Publishers, Sofia, Moscow

Simberloff D, Farr JA, Cox J, Mehlman DW (1992) Movement corridors: conservation bargains or poor investments? Conserv Biol 6:493-504

Skórka P, Settele J, Woyciechowski M (2007) Effects of management cessation on grassland butterflies in southern Poland. Agric Ecosyst Environ 121:319-324

Solmsen N, Johannesen J, Schradin C (2011) Highly asymmetric fine-scale genetic structure between sexes of African striped mice and indication for condition dependent alternative male dispersal tactics. Mol Ecol 20:1624-1634

Stamps JA, Buechner M, Krishnan VV (1987) The effects of edge permeability and habitat geometry on emigration from patches of habitat. Am Nat 129:533-552

Stamps JA, Krishnan VV, Reid ML (2005) Search costs and habitat selection by dispersers. Ecology 86:510-518

Sutcliffe OL, Thomas CD (1996) Open corridors appear to facilitate dispersal by ringlet butterflies (Aphantopus hyperanthus) between woodland clearings. Conserv Biol 10:1359-1365

Tewksbury JJ, Levey DJ, Haddad NM, Sargent S, Orrock JL, Weldon A, Danielson BJ, Brinkerhoff J, Damschen EI, Townsend P (2002) Corridors affect plants, animals, and their interactions in fragmented landscapes. PNAS 99: 12923-12926

Thomas JA (1995) The ecology and conservation of Maculinea alcon and other European species of large blue butterfly. In: Pullin AS (ed) Ecology and conservation of butterflies. Chapman \& Hall, London, pp 180-197

Thomas JA, Elmes GW, Wardlaw JC, Woyciechowski M (1989) Host specificity among Maculinea butterflies in Myrmica nests. Oecologia 79:452-457
Thomas JA, Clarke RT, Elmes GW, Hochberg ME (1998) Population dynamics in the genus Maculinea (Lepidoptera: Lycaenidae). In: Dempster JP, McLean IFG (eds) Insect population dynamics: in theory and practice. Chapman \& Hall, London, pp 261-290

Tischendorf L, Fahrig L (2000) On the usage and measurement of landscape connectivity. Oikos 90:7-19

Tischendorf L, Grez A, Zaviezo T, Fahrig L (2005) Mechanisms affecting population density in fragmented habitat. Ecol Soc 10(1):7. http://www.ecologyandsociety.org/vol10/iss1/ art7/

Trakhtenbrot A, Nathan R, Perry G, Richardson DM (2005) The importance of long-distance dispersal in biodiversity conservation. Divers Distrib 11:173-181

Turchin P (1998) Quantitative analysis of movement: measuring and modeling population redistribution in animals and plants. Sinauer Associates, Sunderland, MA

Van Langevelde F, Wynhoff I (2009) What limits the spread of two congeneric butterfly species after their reintroduction: quality or spatial arrangement of habitat? Anim Conserv 12:540-548

Wahlberg N, Klemetti T, Selonen V, Hanski I (2002) Metapopulation structure and movements in five species of checkerspot butterflies. Oecologia 130:33-43

Witek M, Sliwinska E, Skórka P, Nowicki P, Wantuch M, Vrabec V, Settele J, Woyciechowski M (2008) Host ant specificity of large blue butterflies Phengaris (Maculinea) (Lepidoptera: Lycaenidae) inhabiting humid grasslands in East-central Europe. Eur J Entomol 105:871-877

Witek M, Nowicki P, Sliwinska E, Skórka P, Settele J, Schönrogge K, Woyciechowski M (2010) Local host ant specificity of Phengaris (Maculinea) teleius butterfly, an obligatory social parasite of Myrmica ants. Ecol Entomol 35:557-564

Witek M, Skórka P, Sliwinska E, Nowicki P, Moron D, Settele J, Woyciechowski M (2011) Development of parasitic Maculinea teleius (Lepidoptera: Lycaenidae) larvae in laboratory nests of four Myrmica ant host species. Insect Soc 58:403-411

Wynhoff I (1998) The recent distribution of the European Maculinea species. J Insect Conserv 2:15-27

Wynhoff I, Grutters M, Van Langevelde F (2008) Looking for the ants: selection of oviposition sites by two myrmecophilous butterfly species. Anim Biol 58:371-388

Wynhoff I, Gestel R, Van Swaay C, Van Langevelde F (2011) Not only the butterflies: managing ants on road verges to benefit Phengaris (Maculinea) butterflies. J Insect Conserv 15:189-206

Zollner PA, Lima SL (1999) Search-strategies for landscapelevel interpatch movements. Ecology 80:1019-1030 